\title{
Speaking to Power: The Problem of Enabling Subaltern Voices to Be Heard. A Case Study Concerned with Using the Arts to Engage with the Issue of Maternal Mortality in Western Kenya
}

\author{
Jane Plastow
}

Citation: Plastow, Jane. 2021. Speaking to Power: The Problem of Enabling Subaltern Voices to Be Heard. A Case Study Concerned with Using the Arts to Engage with the Issue of Maternal Mortality in Western Kenya. Social Sciences 10: 471. https://doi.org/10.3390/ socsci10120471

Academic Editors: Lisa Dikomitis, Sally Theobald, F. Zeela Zaizay, Zenawi Zerihun and Shrutika Murthy

Received: 4 October 2021

Accepted: 2 December 2021

Published: 8 December 2021

Publisher's Note: MDPI stays neutral with regard to jurisdictional claims in published maps and institutional affiliations.

Copyright: (C) 2021 by the author. Licensee MDPI, Basel, Switzerland. This article is an open access article distributed under the terms and conditions of the Creative Commons Attribution (CC BY) license (https:/ / creativecommons.org/licenses/by/ $4.0 /)$.
Faculty of Arts, Humanities and Cultures, School of English, University of Leeds, Leeds LS2 9JT, UK; j.e.plastow@leeds.ac.uk

\begin{abstract}
In the context of consistently poor provision of state maternity services to impoverished women in western Kenya over many decades, this article discusses the use of arts in relation to researching subaltern perspectives and enabling subaltern voices to be heard by the powerful. The argument is made that behaviour change agendas are almost always top down, while requirements for the authorities to engage with subaltern voices are minimal and frequently resisted. Case studies are offered of two artistic interventions-a play and a documentary film, made in 2018 and 2019 respectively, which sought to engage medical authorities and the middle classes regarding the consequences of the, sometimes very weak, implementation of Kenya's excellent policies in relation to maternal health for the poor. In conclusion, the question of how to more effectively enable the powerless to speak to power is discussed.
\end{abstract}

Keywords: maternal mortality; Kenya; theatre; film; speaking to power

\section{Introduction}

In western Kenya, large numbers of women and babies are dying, in a large part because of problems with state maternity services. In 2018, I ran a series of two-day, artsbased research workshops to explore the perspectives of service users and close family members on what they saw as the barriers to adequate maternity service provision. Six workshops were initially conducted, each with twenty participants. One included men and women, and all the others were women only, including urban dwellers from the small town of Ahero and women from surrounding villages, with ages ranging from eighteen to fifty. Participants were mainly poorly educated, though they included teachers and a number of high school graduates. All could be defined as poor, as only those lacking financial resource use the free state maternity services.

As a result of these workshops and the stories I heard there, of the poor treatment of women in state-run facilities, and with the active encouragement of many participants, I decided to use my skills as an artist/facilitator/researcher to make two creative works; a play and a television documentary. This would enable the experiences that had been shared with me to be brought to the attention of both those who had direct responsibility for state maternity services: health professionals and politicians, and also to the wider Kenyan middle class public who attend private health facilities and never go to a government clinic or hospital.

I am a British theatre academic who has spent nearly forty years focusing most of my work on East Africa, where I have lived, taught, trained, directed and researched in a number of countries, often running extended community arts programmes over multiple years. In the last twenty years much of my work has focused on making predominantly theatre, but also film and radio, in relation to social problems, as identified by the communities with which I work. On this occasion, I was working as part of a larger project, called Maternal Mortalities in East Africa, run by Irish historian Shane Doyle but drawing 
in, besides me, anthropologists from Uganda, Kenya and Germany, as part of an effort to understand, in a bottom-up study, why the problem of unacceptably high death rates for mothers and babies was persisting across the region.

Rooting my discussion in the experiences of my work in Kenya, I am using this paper to ask questions about why, even when it becomes apparent that social problems across the globe - and I am well aware that this is a massive generalisation-are significantly not individual but stem from structural, organisational or political deficiencies. Researchers (I), NGOs, and in relation to my case, arts activists, so often chose to focus on encouraging individual behaviour change in the relatively powerless, rather than attempting to challenge the relatively powerful by 'speaking to power'. I explore how and why it is difficult to effectively make this choice, but argue that for meaningful change to take place we need to move beyond being satisfied with sitting in comfortable rooms discussing social policy and instead should seek to work with subaltern communities to explore and expose where policies, often highly progressive, are failing in meaningful implementation. Further, I argue that the tendency to put responsibility and blame for poor life choices on subaltern subjects, as implied in much behaviour change activity, is a neo-liberal, individualist strategy that undermines possibilities for building community cohesion and fails to challenge a range of powerful, and ultimately political, entities when they betray their responsibilities and promises to marginalised citizens.

\section{The Health Problem}

High ratios of maternal mortality (MMR) have been recognised as a problem in much of sub-Saharan Africa, over several decades. The third UN Sustainable Development Goal, concerning health and well-being for all, has as its first target the aim to: 'By 2030 reduce the global maternal mortality ration to less than 70 deaths per 100,000 live births' ${ }^{1}$. In Sweden the current number is $2 / 100,000$, while in the US, the industrialised nation with the worst figures, it is 19 . In Kenya the most recent figure is 342, which represents a reduction from 510 in 2015, and is by no means the worst rate on the continent ${ }^{2}$. However, the country is not homogenous, and in western Kenya rates exceed 600 per 100,000, higher than they were in the 1960s (Doyle 2021). In 2013 the Kenyan government committed to providing free maternity services to all women, delivered from a network of state-run clinics and hospitals.

There have been numerous medically based studies undertaken seeking to assist in tackling the problem of the shockingly high number of maternal deaths in sub-Saharan Africa. In 2018, a group of East African and European researchers with backgrounds in both medical and linguistic anthropology, and in history and in theatre (myself), came together to see if a person-centred, as opposed to medically focused, study could offer new and useful insights on the problem ${ }^{3}$.

The project's work focused on $\mathrm{Luo}^{4}$ populations in several adjacent areas, though all theatre work took place only in the Nyanza region. The centre of activity was Ahero, a market town, some twenty kilometres east of the main city in western Kenya, Kisumu, which is situated on the main transport link running from the capital, Nairobi, right through to Uganda. There are a number of large hospitals in Kisumu, but for the communities we were working with, Ahero was the major medical facility. Elsewhere, there were local clinics, some with the sprovision of delivery services, but many of these had limited operating hours and if one needed any kind of operation, such as a Caesarean section, it was necessary to go to Ahero.

\section{Who Speaks to Whom?}

Health organisations worldwide are frequently concerned with encouraging behaviour change in populations to improve health outcomes, whether that be sending out messages about alcohol abuse, encouraging at-risk groups to take an AIDS test or, more recently, conducting campaigns urging the take up of the COVID-19 vaccination. The concept of how one might effectively 'nudge ${ }^{5}$ populations into beneficial changes in health-related 
behaviour has been extensively researched (Hagger et al. 2020). In contrast to the huge number of top-down actions and studies undertaken, studies of how ordinary people can address the powerful to effect behaviour change in their activity are pretty well nonexistent.

Socially purposed arts interventions are also very interested in ideas of behaviour change. For example, in the UK for many years the Theatre in Prisons and Probation (TIPP) Centre ran arts-based courses seeking to promote anger management among inmates (Balfour 2003). In the 1990s many development agencies operating in the political South poured money into theatre productions across sub-Saharan Africa, seeking to urge people to change their sexual behaviour, to get tested and to avoid stigmatising those contracting HIV / AIDS (Plastow 2021, chp. 4). More recently, John Hopkins University and USAID invested in a range of arts programmes working in Africa and ran The Drum Beat Networks, an influential web platform that declares itself a 'Behaviour Change Network' ${ }^{\prime}$. All of these interventions target the poor rather than enabling their voices to critique the powerful.

The one performance form, widely adopted worldwide, which purports to be interested in provoking discussion, and potentially action by the poor, which may include advocating speaking to power, is the Theatre of the Oppressed (TO) (Boal 1974). TO was developed by a Brazilian theatre director and activist, Augusto Boal, in the 1970s, as a theatrical extension of fellow countryman Paulo Friere's thinking, in his highly influential book, Pedagogy of The Oppressed, first published in Portuguese in 1968, challenging top-down educational models. Forum Theatre, where communities are encouraged to critique problematic issues presented in theatrical form, and Legislative Theatre (Boal 1998), developed explicitly to enable ordinary citizens to develop ideas on which they wanted legislative action, and are framed by Boal as 'revolutionary', as they seek to upend the usual transmission of messaging from top to bottom. In contemporary development arts practice. While the forms, especially that of Forum Theatre, has been adopted very widely internationally, the revolutionary intention has rarely been retained. There are some notable organisations, perhaps particularly Jana Sanskriti in India (Ganguly 2010), which have adhered to the original intention of Forum Theatre, but this has not been the case when development agencies adopt the form, where it routinely becomes faux democratic; this is it is ostensibly open to debate but actually pushes specific social and behaviour change messaging and never, to my knowledge, empowers ordinary people to challenge more than very local leadership (Plastow 2009) ${ }^{7}$.

There is, of course, a long tradition of political art across the globe-film, theatre and literature, etc., which takes on the ruling classes. Most notably in Kenya itself, we have the work of Ngugi wa Thiong'o and the community members of Kamiriithu, who made two enormously influential and enormously contentious, plays in the late 1970s and early 1980s, critiquing the hyper-capitalist, neo-colonial policies of the first Kenyan post-independence government; for their pains they saw their carefully constructed homemade theatre razed and their leadership forced into exile (Bjorkman 1989; Wa Thiong'o 1981). There is a fine line between overtly political theatre and enabling communities to use the arts to speak to power. However, I would note that to pretend that any behaviour change activity does not have a relationship to the political, however reluctant researchers may be to routinely acknowledge this, is disingenuous.

In the case of my work in Kenya, the community members who wanted to be able to speak to power never evinced any interest in political parties or in challenging the right of their leaders to rule; they never constructed their thoughts in an ideologically inflected manner. Indeed, they were never asking for anything that had not officially already been given to them. Kenyan policies, on both free maternity care for all, and on how that care should be delivered, are codified and exemplary ${ }^{8}$. The problem for maternity care was that too many were failing to look beyond the achievement of good policy to understand how poorly implementation was taking place. This implementation myopia appeared to afflict both politicians and medical authorities. The then regional Minister for Health, Dr. Rosemary Obara, told me that she very much wanted to hear people's perspectives on 
maternity care, but when I hand-delivered extremely polite but incisively critical letters from women who had endured problems in using state services, she sought to close down our work. A high-level meeting of medical authorities concerned with gynaecological matters held in Kisumu in August 2018 was more open, but discussion tended to focus on the lack of technology to deal with complicated cases and looking to what was happening in the major city referral hospitals rather than trying to understand the grassroots perspective, which was much more concerned with local ante- and post-natal clinics and with the acute difficulties of getting five miles down a dirt track when you have no transport and need a hospital delivery.

There are officially a number of forums in Kenya through which people can express their views on the health treatment. Ahero hospital has fairly prominently displayed notices inviting people to contact them if they have any complaints. All these notices are in English, a language relatively few of those I encountered in my study can speak or read well, and no one ever suggested that writing to the hospital authorities might be productive. There is also meant to be a community forum run from the hospital, but in all the months I was visiting I heard of no activities and none of the perhaps two thousand people who were involved in various elements of our research and community outreach work had ever heard of this organisation.

\section{The Problems in Speaking to Power}

The central problem in speaking to power is that the powerful like critique no more than most of the rest of us, but they are often in a more privileged position when it comes to resisting or even shutting down those who question them, especially when the challengers are poor and uneducated. This is one reason for using group art forms to undertake speaking to power, as a community group is always going to be less vulnerable than an individual, particularly if they have outside backing, in the case discussed here by our project, as an internationally funded and staffed piece of research. On the basis of the experiences discussed below, I would theorise that there are two main strategies to be invoked if the poor want to reach the powerful. The first, illustrated in my first example, is that one can try to engage the empathy of the powerful. The second is that one can seek to publicly confront and expose them so that they are forced to take action. This was what was attempted in my second example. The outcomes will become clear.

When I began work on Maternal Mortality in East Africa there was no intention to involve ourselves in speaking to power activity. The intention was to learn from and engage subaltern communities in relation to securing adequate maternity services. Both the play and the documentary film I discuss below were created because the treatment, particularly of poor women and, to a lesser extent, of nursing staff, was perceived by both groups to be highly problematic, as it was frequently dangerous to the health and even the lives of women and babies and in significant contradiction to the stated intentions for maternity services in the country. Nurses had often, and recently, taken fairly extreme action in support of their claims for better pay and conditions, including periods of prolonged strike action, which had led to increased deaths in childbirth, resulting in very little positive action (Waithaka et al. 2020). Poor women and their wider communities appeared to have no effective opportunity to get their voices, insights and perspectives heard.

This is a situation that recurs time and again when working with marginalised communities in the political South. When working in both Asia and Africa a little digging has often uncovered progressive, even exemplary, policy documents relating to issues such as health and education-policies which all too often bear no relation to the realities experienced on the ground. Policy is of course important, but I have become highly sceptical of the stress laid by development agencies and by the research bodies from which I get my own funding, on the importance of working with policy makers accompanied by a complete absence of discussion about how it might be ensured that these policies are implemented. In the Kenyan case there were two obstacles to policy implementation. One was undoubtedly political. The state has simply not been putting in sufficient money to be able to deliver on 
the promises of comprehensive free healthcare that it has made and regional governments do not always disburse the funds they are given to support these aims (Owino et al. 2020). Secondly, everyone I spoke to agreed that the doctor's lobby and organisation was extremely powerful. It is common knowledge that most doctors supplement their state wages by running private medical practices, and equally common knowledge that very many doctors do not fulfil their contractual obligations in state health facilities if these either interfere with private practice or inconvenience the doctors (Tumlinson et al. 2019).

\section{Researching Subaltern Perspectives on Maternity Services}

While my fellow researchers were conducting focus groups, interviews and analysing medical records concerned with the experiences of poor women in western Kenya-the more affluent would always use private health facilities-I approached the problem from an arts-based perspective. Initially, this involved running the two-day arts-based workshops discussed in the Introduction. The advantage of such an approach-which was subsequently taken up by my anthropological colleagues-is that it promotes a relaxed, community-centred space for exploration and analysis of community problems, which leads to a rich trove of relevant research.

Our days always began with games; games to introduce ourselves and to learn a little about each other and games to get voices and bodies active and engaged so that all would be primed to contribute. I had explained to the women that I saw them as co-researchers; people who would not only provide data but would work together with me to sift what was most significant in the stories they agreed to share. Over the years I have collected a panoply of participatory exercises to help me understand community perspectives on the issues I am researching, but central to these is the sharing of stories. In this instance, I asked women to tell me two kinds of stories; stories that illustrated problems they experienced in their home communities in being supported through pregnancy and childbirth and stories that spoke to issues they might have experienced with medical professionals.

The community-centred stories led in due course to a series of thirty performance/ workshops in a contiguous spiral of rural hamlets. Women had shown and said, time and again, that in this patriarchal, age-hierarchical society, they were not free agents when it came to making choices about their sexual and reproductive health. This was particularly true in rural settings, so even when women had received some of the often patchy information on offer at ante-natal clinics to help them look after themselves in pregnancy, they were often not able to act on it because senior family members put barriers in the way. Women therefore asked that our work should seek to engage husbands, who they told us saw pregnancy as a matter of purely female concern, and mothers-in-law, powerful figures in a society where young couples are expected to move to a house constructed for them within the husband's parents' compound, who we were told were often suspicious of attendance at health clinics and hospitals. I have written elsewhere about the unexpected levels of positive engagement with these workshops, where time and again community members showed that a major barrier to supporting pregnant women was poverty of information, a poverty most were eager to rid themselves of and where subsequent evaluation showed many concrete examples of positive behaviour change from husbands and mothers-in-law, but also from older men and traditional birth attendants (Plastow and Elliott 2020). Indeed, the impact of the workshops and strongly, repeatedly expressed desire for more similar events has enabled us to secure further funding to develop this approach in 2021 in a larger group of villages ${ }^{9}$.

The stories I heard about problems with medical services required different solutions. When asking people to share their experiences I always emphasise that I am not looking for the sensational and that people should only speak of events they are happy to share with the world. I consider it unethical and that it might run the risk of re-traumatising people to ask for more profound tales. In this case it would have been quite sufficient to mention the long queues commonly experienced at ante-natal clinics or the sometimes brusque attitude of many medical staff towards poor women. However, while I did hear such stories, by far 
the majority of experiences shared and the ones the women wanted to discuss at length, to show in whole group sessions and to ask the authorities to address, related to much more serious happenings.

The focus of the women's concern was their treatment by nurses when delivering their babies. Most of these experiences took place at Ahero referral hospital. The stories I was told listed a series of abusive practices. Some of the abuse was verbal. A young girl would be lectured on her sinfulness in getting pregnant when she should be in school and might be badgered for the name of her lover. One lady told of going to deliver her fifth child at the age of forty-eight and being mocked for being so elderly. Making noise while in labour could also bring down nurses' wrath. Physical abuse took place when nurses thought women were not putting sufficient effort into delivering their babies, and even a senior nurse trainer told me that it was felt appropriate to slap such women to make them focus on the job in hand. The general perception was that nurses despised rural, illiterate women; that they often failed to speak to them respectfully or to explain what was going on, and that they preferred to spend their time on shift gossiping, attending to women's needs only when they were pressingly urgent. Perhaps most shocking were various tales I was told of women being turned away from treatment if they were in extremis. Hospitals have to report all deaths and I heard of several occasions where women were told to get themselves to Kisumu if Ahero felt it could not cope, without any offer of an ambulance, or where dying women were smuggled off the premises.

\section{Speaking to Power-A Play}

I wondered just how aware senior medical professionals were, either of women's perspectives or of what was going on day-to-day in state delivery wards. An opportunity to try to find out, and to illustrate some at least of the stories I had heard, came when our project held a high-level meeting in August 2018, in Kisumu, to explain our project and to understand contemporary gynaecological thinking. I proposed that we put on a play, based on the women's experiences, showing their critique of the current state of affairs. This had not been written in to the original project plan but Doyle was happy to support the work, though he did confess afterwards that he was rather worried that the play would alienate his audience.

My actors were not the women themselves but the Ahero-based semi-professional theatre company, and project partners, Lagnet Cric. Lagnet had at this time been operating for some twenty years, working on a range of applied theatre projects for local, national and international funders, and I had met them a couple of years previously. The company itself was my guinea pig for the two-day workshops and then helped me facilitate the others; they took notes on all the stories shared and discussed points raised, helping the women to dramatize some of their work. Importantly, most were themselves part of the communities we were seeking to engage, and had experienced many of the issues recounted in later workshops, so that they were able to strongly identify with the show we made.

We had only a week to make the play. I drafted an outline that was based on the stories I had heard. It would centre around three women who had come to the Ahero hospital to give birth: a teenage unmarried girl expecting her first child, an older woman coming for her fifth delivery and a woman who is initially sent away as she is told her labour is insufficiently advanced for her to be admitted. The delivery ward was staffed by two nurses, more interested in chatting about their private lives than in their patients, while a lone doctor put in only very occasional appearances. My outline was discussed and modified in consultation with Lagnet. We then had just three days to rehearse.

Much was devised around the scenario. The company adapted a well-known tune to become a mourning song that framed the performance and all the actors were given the opportunity to name someone they knew who had died in childbirth to whom they were dedicating their performance. The nurses managed to create an atmosphere that was simultaneously hilarious and horrific as they discussed getting their nails painted while patients begged for assistance, and in a Brechtian adaptation I got everyone to learn quotes 
from the Kenyan National Guidelines for Quality Obstetrics and Perinatal Care that spoke of compassion, respect and women's rights and were painted onto placards ${ }^{10}$. Only one woman died in the play, but all were abused and ignored for much of their delivery, while the dead woman was smuggled out of the facility in an attempt to cover up what had happened to her.

I spent much of the performance watching the audience. The nurses elicited much laughter, but there were also tears from a surprising number of senior medical figures. A play is both an intellectual and an emotional experience, and indeed I would argue that this is a significant strength for artistic work in relation to speaking to power. A couple of years earlier I had made another play targeting authority figures in Uganda in relation to the corruption and bureaucracy involved in the process of acquiring the freehold to previously council-owned properties for slum dwellers, who ostensibly had the right to buy the houses they had been renting for very favourable prices, but who had to pay bribes at every point of what we identified as a 17-stage process. When the town clerk of Jinja, the city concerned, saw the play, he was reduced to tears, saying: "When you act we were really touched, we are all pledging to work for you, we watch this without bad blood. We cannot look away". He subsequently not only ensured that the production was seen in a command performance for all members of the council, but also took steps so that we won the modest victory of seeing two of those stages expunged. While he may not have been aware of every aspect of his people's struggles to acquire property the mayor was certainly knowledgeable regarding some of what was going on. It was his emotional identification with the plight of 'real' people that led him to take action in this instance.

It is also important that those in power recognise what they are seeing as 'truth'. In both Uganda and Kenya, our interventions met this standard. I was not able to be around as much after the Kisumu play's completion as I had to look after the needs of the actors, but Doyle told me that several people told him, "This is what it is like", and that a number of people discussed how similar performances might be useful to engage a wider public with the issues being experienced in state maternity services (Personal communication 25 June 2021). Finally, and I have no proof of this assertion, I think that the serious message at the heart of both productions was made more palatable because both incorporated comedy, with the laughter balancing out tears and condemnation to make the shows easier for the powerful to accept ${ }^{11}$.

\section{Speaking to Power-A Documentary Film}

Emotion is not important only for audiences. When I returned to Britain after my first piece of research for Maternal Mortalities I remained both haunted by, and angry about, the experiences women had shared with me. I then saw a funding opportunity being made available to my university, Leeds in the UK, via the national Global Challenge Research Funds and I successfully applied for money to make a documentary film. My inspiration for this piece of work was my knowledge of the impact that has been made over the years by investigative documentary films for British television such as Panorama, which have at various times roused public opinion on matters, such as abusive behaviour by staff in homes for senior citizens and for people with learning difficulties, to such an extent that the authorities have been forced to take action ${ }^{12}$. If this form could be so powerful in Britain, perhaps getting a documentary on Kenyan TV, revealing the equally abhorrent situations that poor pregnant women were enduring, something far distant from the experiences of the affluent television-owning middle classes, might equally lead to an outcry the state could not ignore. The television documentary is not a strong form in Kenya and I had never made a television documentary, so this was a new departure in several ways in terms of trying to find effective ways to speak to power.

The film crew that was to make the film, over three months in 2019, was composed of myself; Dr. Simon Peter Otieno, a lead film lecturer at the University of Nairobi, who has pioneered film-making in schools in Kenya to such an extent that there is now an annual Kenyan Schools Film Festival; and William Nyerere Plastow and Tina Tschismarov, 
British-Tanzanian and Austrian documentary film makers, respectively, who, through their production company, Gravel \& Sugar, had previously worked with me in Uganda on a number of film training projects.

We already had a raft of research agreements with the various Kenyan medical authorities and early on in our process we visited the regional Health Minister, Dr. Rosemary Obara, and the regional Governor, Professor Peter Nyong'o, who agreed to support our work. These authorities were vital in getting us access to all the relevant areas of Ahero Hospital. The previous research had enabled us to understand the perspective of hospital patients, but we now needed to understand what the situation looked like from a medical practitioners' point of view. We conducted multiple interviews with a wide cross-section of hospital staff, but most important was gaining the trust of the nurses working in midwifery. This was not difficult. The staff were very willing to talk about the difficulties of their roles. A key factor was understaffing, coupled with low wages and status, and a lack of vital resources, such as blood for transfusions and the difficulty of getting doctors to attend problematic deliveries, especially during night shifts, when on-call doctors and anaesthetists, who routinely refused to stay in the hospital even though an on-call room with sleeping facilities was provided, often failed to turn up if telephoned for urgent assistance.

Our film had two major elements. The hospital-focused section followed the night shift, with the hugely experienced midwife, Sister Monica Munala, working a fourteen hour stint. On the shift we ended up profiling Sister Monica, who was in charge of not only delivery, but also the post-delivery ward and paediatrics, was assisted by just a single trainee. The film showed her delivering a baby to a woman who had come in alone on a motorbike taxi, which she had fallen off along the way, making the delivery potentially dangerous. Repeated phone calls produced no doctor, even though the hospital had been alerted that another patient, needing a Caesarian section, was headed their way. The on-call ambulance driver explained that much of the time his work consisted of going into Kisumu to pick up doctors who refused to stay in the hospital or drive their own cars.

The story at the heart of the other major element of our documentary came out of the research workshops with local women. Here we heard about a woman who died in childbirth, along with her baby, outside the hospital gates, having been refused admittance. Verifying the elements of Judith Awino's story took much time. Our superb local fixer, Josephat 'Obul' Onyango, tracked down Judith's husband, Denis, who lived in a rural hamlet some eight kilometers from Ahero, down a dirt road. We then became engaged in an at times Kafkaesque process, in trying to understand the story in depth and to verify the facts as much as possible. This was complicated by feuds between different parts of the extended family, reluctance on the part of various people connected with the hospital to speak freely about what went on that night in question, and even witchcraft issues, where some people suspected that we were members of the Illuminati, something widely believed in across the region as a shadowy Satanist conspiracy.

As finally agreed, we told of the last twenty-four hours of Judith's life. She was a twenty-five-year-old who, one night in 2017, went into labour with her second child. She had attended all her ante-natal appointments and had had no problems with her first labour. The timing for getting any help was appalling. Kenya had just held elections and, as often happens, there was considerable post-election violence in this Luo region, which has often contested the legitimacy of the Kikuyu, capital-based presidents ${ }^{13}$. This was one reason why Judith intended to have a home birth. The second was that at the time there was a six-month strike of nurses going on, in protest at poor pay and conditions. After some twelve hours of labour it was evident that there were problems, not least that the baby was stuck, with one arm protruding from its mother.

Late in the cold, thinly raining evening Judith was loaded onto a donkey cart and taken to the traditional birth attendant. She immediately saw the case was beyond her competence and told Denis that his wife must be taken to a medical facility. This meant a five-kilometre walk down rutted tracks, which the rain had turned into a quagmire. The family set off with Denis, Judith's mother and a young male cousin in attendance. At the 
main road they knocked in vain at a small private clinic, where the watchman told them they had to go on a further three kilometres to Ahero Hospital. By this time Judith was, rightly, convinced she was dying, but the family had no choice. They went on.

In the early hours of the following day they arrived at Ahero. They begged admittance of the gate guard, who went to speak to people inside the facility. He then returned to tell them they could not come in. Vain attempts were made to reach another clinic and then to ask the police-uselessly-or to get money-equally uselessly-for help to get into the city of Kisumu. As dawn broke, Judith died at the gates of Ahero Hospital.

The scandal we uncovered, thanks to one of the women from our original participant research group, was that while there were no nurses on duty because of the strike, in the hospital at the time there were medical officers, a Kenyan grade of medical professional situated between a nurse and a doctor. She knew this because on that same night she had taken her son into the hospital to get help from one of the medical officers who was, quite illegally, running a private practice from the facility during the strike.

Our film, Sunset at Dawn, runs for some thirty minutes. The hospital-based section is in observational documentary format, while Judith's story is told partly through interviews with key players and partly through recreations performed by members of Lagnet Theatre. It concludes by broadening out to interviews with senior national personnel, making the point that these problems are by no means unique to this particular part of Kenya.

We had to leave Kenya after shooting and it took a few months to edit the film. I then went back to the country and held a number of preview screenings. It was hugely important that the key players agreed that the film represented the truth of both Judith's story and of the situation in relation to the maternity service delivery in the region. Therefore, we showed the film in Ahero to Lagnet and invited guests, including grassroots level local politicians, who all agreed that the film was highly representative of the local reality. With some difficulty we took a generator and the necessary equipment out to Judith's village, where we ran another screening. This was a highly emotional occasion for many, as it brought back so many bitter memories, but the endorsement for the work was universal.

Then, I took Sunset at Dawn into Ahero Hospital. I was well aware that this was likely to be a tricky occasion. Everyone involved in the film had had the nature of our work explained to them and had signed consent forms. However, it is undoubtedly the case that all were somewhat naïve about how their actions might look on screen. At Ahero, the film was shown to all who had been interviewed with some other interested staff in attendance. Reactions were deeply split. The nurses and midwives were very happy with how their travails and excessive workload were portrayed. The doctors and medical officers were stony faced. The question of permissions and consents was raised. When these were irrefutably answered they turned to an ethical line. It was queried if it was permissible to show a woman giving birth, even though the lady in question had agreed and signed a consent form. The showing of her genital area was deemed improper (I had to explain that in the final cut this would be blurred). There was great upset that in the course of her phone calls seeking to get the on-call doctor, Sister Monica mentioned his name. I was reluctant to obscure this, but eventually agreed since our target was not a particular medic but the much more widespread practice of failing to attend rostered duty calls.

A final Kenyan screening at Nairobi University, for mostly privileged film students, garnered yet a different set of feedback responses. The few poorer students were very enthusiastic, saying the film reflected realities in their communities. Many of the more affluent were quite stunned. It was evident, as I had thought, that they had very little idea of what went on in state medical facilities. Reaction amongst this group was split. Some thought this was an important film that needed to be shared, while a few argued that foreigners always showed negative aspects of Kenyan society and that we should have made something more upbeat.

Back in the UK final adjustments were made to the cut that would go forward for screening and then the documentary was sent both to the Kenyan Television Authority to get permission for screening and to Citizen TV, the major independent television station 
which had already kindly given us, for free, various news clips showing both the political violence and nurse strike, and with which we had been discussing the projected public screening. Official authorisation was not a problem. Otieno, who organised this part of the process, told us that the woman who viewed and authorised the film told him she had been in tears when watching it and said to him that this was an important documentary that must be shown. However, totally unexpectedly, the television station suddenly decided that we should be treated like an INGO and charged $£ 8000$ to have our film shown. The director of the station we had been dealing with said he was powerless. I did not have $£ 8000$. The film could not be shown.

Otieno then started exploring alternative outlets and came up with Rambo TV, a smaller outfit, which particularly seeks to target younger women and thought our documentary might be of great interest to their viewers. I met the young director and we agreed that prior to screening there would be a discussion programme about the work. I was asked to organise a panel of three men and three women to hold a debate, which would be followed by the screening. The women were no problem. Sister Monica would be joined by another Monica, a widmifery trainer, who also featured in the film discussing the problem of under-recruitment of nurses for state maternity services. They were joined by a female volunteer community health worker and a member of Lagnet, who had participated in all stages of our work. The men were another matter. I knew none of the doctors or medical officers from Ahero would attend. With help from Doyle, who suggested various senior medical figures, I eventually got two senior doctors to agree to join us and the panel was completed by a young film student from a poor background who knew the kind of issues raised in our work from a community perspective. All were sent the film to watch before the day of the programme. I was in the UK and very excited to hear how both discussion and screening would go.

Around 11am, on the day the debate was to be recorded, I was surprised to get a phone call from Kenya. It transpired that not everyone had viewed the film in advance and so the TV station had had to organise a private viewing. The doctors were not happy. I was stunned, and found myself conducting a group call to try to allay their concerns. Both the doctors tried to play the ethical card. They rehearsed the same arguments that medics had brought up in Ahero, trying to claim that their main worry was the showing of a woman giving birth. I was more concerned when I spoke to the two Monicas. It was evident that they had been heavily leaned on from above. They now wanted to back out of the film because they said they were frightened they would lose their jobs. I do not know who was responsible for the pressure but both women were distinctly panicked. After half an hour's conversation that was going nowhere, the two doctors said they were not going ahead with the discussion and the midwives followed suit. Suddenly there was no discussion programme and the TV station then pulled the screening of the documentary.

As I write, and as a result of being stuck in UK because of COVID-19, the plan to show the film on a national TV station has got no further and I am now waiting to go back to Kenya to discuss the best way to share the film via popular social media forums. The whole saga has thrown up a range of questions-about the power of the medical profession, about investigative documentary making in Kenya and about speaking to power.

\section{Conclusions}

I do not have neat answers to many of the issues raised in this article. I do, however, have some questions that I ask both of myself and of a host of other researchers concerned with social policies, implementation and behaviour change agenda.

(1) Why does so much research time and money get spent on promoting policy engagement and so little, relatively, on supporting implementation or checking if proper implementation is taking place?

(2) Why is behaviour change almost always constructed as a top-down model and so seldom applied to the powerful? 
(3) What strategies can we develop to more effectively speak to power concerning a range of social policy concerns?

I think, in relation to my first two questions, the answers have much to do with two factors. Firstly, both researchers and aid agencies are often, understandably, nervous of encroaching on what might be perceived to be political matters, both because this might be seen as being beyond their remit and because their activity might be closed down. However, if this is the case, we need to be transparent about the matter to ourselves and to the communities of the poor we may purport to support, assist or even represent. Secondly, and this is possibly more controversial, it seems to me that too little social research is deeply concerned to engage with and understand the perspectives of the poor and to ally with them, as opposed to enjoying engagement with the rich and powerful. Informationgathering techniques are commonly employed, such as rapid rural appraisal (RRA) or a series of one-off interviews or focus groups, can indeed garner much useful information, but they do not require the kinds of embedded, long-term or processual engagement, which are needed to understand and empathise with the multi-faceted marginalisations, disempowerments and obstacles facing poor communities worldwide, so that research can begin to appreciate the absolute need to partner with such groups, to truly work with, as opposed to for, them, and to support them in enabling subaltern voices to be heard in the decision-making chambers of power.

In relation to my third question, this article has discussed two strategies I have sought to invoke with mixed, but definitely limited, impact. I have come to realise that speaking to power needs more careful strategy and forward planning than I have applied to it in the past. This conclusion then is in the nature of a suggestion, that we need to pay more attention to speaking to power and to considering how, when, why and where it might more effectively be undertaken so that some of the social transformations so many academics are theoretically committed to may have a chance of actually taking place.

Funding: The funding that supported the work that gave rise to this article was provided by the Medical Research Council, the Arts and Humanities Research Council and the University of Leeds. Maternal Mortality in East Africa; AHRC-MRC Global Public Health Partnership (MR/R024502/1) Research England Allocation for Global Challenge Research; University of Leeds.

Institutional Review Board Statement: The study was conducted according to the guidelines of the Declaration of Helsinki, and approved by the Ethics Committee of the University of Leeds. Approval code PVAR 17-095 Awarded 12 March 2018.

Informed Consent Statement: Not applicable.

Data Availability Statement: Data not currently publicly available.

Conflicts of Interest: The author declares no conflict of interest.

\section{Notes}

See https://sdgs.un.org/goals/goal3, 9 September 2021.

See https:/ / www.who.int/news-room/fact-sheets/detail/maternal-mortality+9?@-, 9 September 2021.

This research was jointly funded by the UK's Medical Research Council (MRC) and the Arts and Humanities Research Council (AHRC). The research team was led by historian Shane Doyle, and included three anthropologists; the German, Paul Geissler; the Kenyan, Benson Mulemi; and the Ugandan, Saudah Namyalo. I was the theatre specialist.

4 The Luo are the fourth largest linguistic group in Kenya, living in an area abutting Lake Victoria in the west of the country and over the border in Tanzania. Some 5,000,000+ people make up just over 10\% of the national population. They speak a Nilotic language Dholuo.

5 The highly influential 2008 book, Nudge, by Richard Thaler and Cass Sunstein, led to a flurry of publications about how to influence populations, widely taken up by politicians in a number of countries.

6 https://www.comminit.com/health/content/drum-beat-networks, 9 September 2021.

7 In 2014 theatre students at Moi University in Kenya used Forum Theatre to address problems of insecurity on the campus which led to major beneficial reforms (Personal communication; Christopher Odhiambo. 30 August 2021). 
The Kenya 'National Guidelines for Quality Obstetrics and Perinatal Care', http:/ /guidelines.health.go.ke:8000 / media/National_ Guidelines_for_Quality_Obstetrics_and_Perinatal_Care.pdf, 9 September 2021 are exemplary.

9 Thanks to UK Arts and Humanities Research Council for supporting this 'Follow-On' work.

10 Examples of quotes we painted on placards from the guidelines included: 'Clients have a right to be treated with courtesy, consideration and attentiveness' (p. 21). 'When the mother comes into labour, the health service provider must provide a supportive, encouraging atmosphere for the birth' (p. 173).

11 For further information on this work see (McQuaid and Plastow 2017).

12 See Panorama: When the Caring Stops, May 2014. https:/ /www.youtube.com/watch?v=Lp5twji3pk8, 9 September 2021 and for action taken as a result see https:/ / www.communitycare.co.uk/2019/05/23/reaction-panorama-programme-abuse-learningdisability-hospital/, 9 September 2021.

13 See https://www.hrw.org/news/2017/08/27/kenya-post-election-killings-abuse, 9 September 2021.

\section{References}

Balfour, Michael. 2003. The Use of Drama in the Rehabilitation of Violent Male Offenders. Lampeter: Edwin Mellen Press.

Bjorkman, Ingrid. 1989. Mother, Sing For Me: People's Theatre in Kenya. London: Zed.

Boal, Augusto. 1974. Theatre of the Oppressed. London: Pluto Press.

Boal, Augusto. 1998. Legislative Theatre: Using Performance to Make Politics. London: Routledge.

Doyle, Shane. 2021. Maternal Health, Epidemiology and Transition Theory in Africa. In Epidemiological Change and Chronic Disease in Sub-Saharan Africa: Social and Historical Perspectives. Edited by Megan Vaughan, Kafui Adjaye-Gbewonyo and Marissa Mika. Chicago: University of Chicago Press.

Ganguly, Sanjoy. 2010. Jana Sanskriti: Forum Theatre and Democracy in India. London: Routledge.

Hagger, Martin S., Linda Cameron, Kyra Hamilton, Nelli Hankonen, and Taru Lintunen, eds. 2020. The Handbook of Behavior Change. Cambridge: Cambridge University Press.

McQuaid, Katie, and Jane Plastow. 2017. Uganda-From Research to Activism: Theatre and Anthropology in Walukuba. Critical Stages 15.

Owino, Lisa, Annette Wangong'u, Nerima Were, and Allan Maleche. 2020. The missing link in Kenya's universal health coverage experiment: A preventive and promotive approach to SRHR. Sexual and Reproductive Health Matters 28: 1851347. [CrossRef] [PubMed]

Plastow, Jane. 2009. Practising for the revolution? The influence of Augusto Boal in Brazil and Africa. Journal of Transatlantic Studies 7: 294-303. [CrossRef]

Plastow, Jane. 2021. A History of East African Theatre. London: Palgrave Macmillan, vol. 2.

Plastow, Jane, and Matthew Elliott. 2020. Translating 'good' pregnancy in Rural Nyanza, Kenya. Moving Worlds 20: 83-96.

Tumlinson, Katherine, Margaret W. Gichane, Siân L. Curtis, and Katherine LeMasters. 2019. Understanding healthcare provider absenteeism in Kenya: A qualitative analysis. BMC Health Services Research 19: 660. [CrossRef] [PubMed]

Wa Thiong'o, Ngugi. 1981. Writers in Politics. Nairobi: East African Publishers.

Waithaka, Dennis, Nancy Kagwanja, Jacinta Nzinga, Benjamin Tsofa, Hassan Leli, Christine Mataza, Amek Nyaguara, Philip Bejon, Lucy Gilson, Edwine Barasa, and et al. 2020. Prolonged health worker strikes in Kenya-perspectives and experiences of frontline health managers and local communities in Kilifi County. International Journal of Equity Health 19: 23. [CrossRef] [PubMed] 